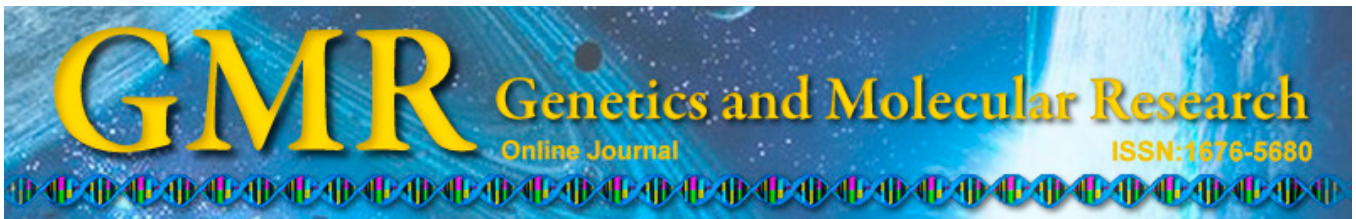

\title{
Selection indices to identify drought-tolerant grain sorghum cultivars
}

\author{
C.B. Menezes $^{1}$, C.A. Ticona-Benavente ${ }^{5}$, F.D. Tardin ${ }^{1}$, M.J. Cardoso ${ }^{3}$, \\ E.A. Bastos ${ }^{3}$, D.W. Nogueira ${ }^{2}$, A.F. Portugal ${ }^{1}$, C.V. Santos ${ }^{4}$ and \\ R.E. Schaffert ${ }^{1}$ \\ ${ }^{1}$ Embrapa Milho e Sorgo, Sete Lagoas, MG, Brasil \\ ${ }^{2}$ Universidade Federal de Lavras, Lavras, MG, Brasil \\ ${ }^{3}$ Embrapa Meio Norte, Teresina, PI, Brasil \\ ${ }^{4}$ Universidade Federal de São João Del-Rei, Sete Lagoas, MG, Brasil \\ ${ }^{5}$ Instituto Nacional de Pesquisas da Amazônia, Manaus, AM, Brasil \\ Corresponding author: C.B. Menezes \\ E-mail: cicero.menezes@embrapa.br
}

Genet. Mol. Res. 13 (4): 9817-9827 (2014)

Received January 16, 2014

Accepted June 17, 2014

Published November 27, 2014

DOI http://dx.doi.org/10.4238/2014.November.27.9

ABSTRACT. Twenty-five cultivars of grain sorghum [Sorghum bicolor (L.) Moench] were examined under both drought stress and normal conditions in 4 experiments. In each condition, genotypes were evaluated in a factorial experiment using a randomized complete block design with 3 replications. Eight drought tolerance indices including stability tolerance index, mean productivity (MP), geometric MP, harmonic mean, stress susceptibility index, tolerance index, yield index, and yield stability index were estimated for each genotype based on grain yield under drought (Ys) and irrigated conditions (Yp). The results indicated that there were positive and significant correlations among Yp and Ys with geometric MP, MP, harmonic mean, and stability tolerance index, indicating that these factors are better predictors of Yp and Ys than tolerance index, stress susceptibility index, yield stability index, and yield index. Based on adjusted means at Yp and Ys, indices geometric 
MP, MP, harmonic mean, and stability tolerance index, unweighted pair group method with arithmetic mean cluster and biplot analysis, the most tolerant cultivars were '9929020', '9929034', and 'N 95B'.

Key words: Abiotic stress; Drought stress; Sorghum bicolor; Sorghum breeding; Sorghum yield

\section{INTRODUCTION}

The area used to plant grain sorghum in Brazil has increased in recent decades. Major production areas are in southeast region in the States of Goiás, Mato Grosso, and Minas Gerais. Although the national average yield is $2.6 \mathrm{t} / \mathrm{ha}$ (CONAB, 2013), the results of experimental trials indicate that this yield can be doubled if growers follow technical crop management guidelines.

Sorghum yields have not increased or have even declined because production is being pushed into more marginal areas and poorer soils. In Brazil, sorghum is grown as a succession crop after soybean. After harvesting the soybean, a farmer begins sowing corn in late January and early February. Sorghum is planted in the rest of the area when the risk of planting corn is high because of drought stress, and in most of the times without any fertilizer. Therefore, the development of drought-tolerant sorghum cultivars producing more stable for yield is essential for guaranteeing the success of the sorghum crop in these areas.

Drought may be the most important abiotic stress limiting crop productivity worldwide, including Brazil; in Brazil, sorghum is typically grown when rainfall is generally low or its distribution is erratic. The crop season often has a normal rain start but terminates prematurely, thereby exposing the crop to post-flowering stress.

Identification of lines with high levels of post-flowering drought tolerance and the selection of these lines for higher yields are very important for sorghum breeding.

The relative yield performance of genotypes in drought-stressed and non-stressed environments appear to be a common starting point for identifying desirable genotypes for unpredictable rainfall conditions (Mohammadi et al., 2010). Various conditions must be considered during the selection process: a) under non-stressed conditions, b) under target stress condition, and c) a mid-point under both none and stressed conditions (Betrán et al., 2003; Golabadi et al., 2006; Mutava et al., 2011). Drought resistance was defined by Hall (1993) as the major relative yield of a genotype compared with other genotypes subjected to the same drought stress. Drought susceptibility of a genotype is often measured as a function of the reduction in yield under drought stress (Blum, 1988), while the values are confounded with the differential yield potentials of genotypes (Ramirez and Kelly, 1998). Several indices were utilized to evaluate the genotypes for drought tolerance, which are shown in Table 1.

Typically, the efficiency of these indices are evaluated in one local environment without considering the genotype-environment interaction. Thus, it is necessary to evaluate this effect for choosing the best indices for genotype screening. Selection of different genotypes under environmental stress conditions is a priority of plant breeders for exploiting genetic variability to improve stress-tolerant cultivars.

The present study was conducted to assess selection indices for identifying drought tolerance in grain sorghum genotypes considering the environmental effect, as well as to select the best genotypes that are stable under both stressed and non-stressed conditions. 
Table 1. Drought tolerance indices to evaluate the reaction of sorghum lines.

\begin{tabular}{|c|c|c|}
\hline Drought tolerance indices & Equation $^{1}$ & References \\
\hline 1.Stress susceptibility index & $\mathrm{SSI}=\frac{1-\left(\frac{\mathrm{Ys}}{\mathrm{Yp}}\right)}{1-\left(\frac{\overline{\mathrm{Y}} s}{\bar{Y} p}\right)}$ & Fischer and Maurer (1978) \\
\hline 2. Geometric mean productivity & $\mathrm{GMP}=\sqrt{\left(\mathrm{Ys}_{\mathrm{s}}\right)(Y p)}$ & Fernández (1992) \\
\hline 3. Mean productivity & $\mathrm{MP}=\frac{\mathrm{Ys}+\mathrm{Yp}}{2}$ & Rosielle and Hambling (1981) \\
\hline 4. Harmonic mean & $\mathrm{HM}=\frac{2(\mathrm{Yp} \cdot \mathrm{Ys})}{Y p+Y s}$ & Jafari et al. (2009) \\
\hline 5. Tolerance index & $\mathrm{TOL}=\mathrm{Yp}-\mathrm{Ys}$ & Rosielle and Hambling (1981) \\
\hline 6. Stress tolerance index & $\mathrm{STI}=\frac{(\mathrm{Ys})\left(Y_{p}\right)}{\left(\bar{Y}_{p}\right)^{2}}$ & Fernández (1992) \\
\hline 7. Yield index & $Y I=\frac{Y_{S}}{\bar{Y}_{S}}$ & Gavuzzi et al. (1997) \\
\hline 8. Yield stability index & $Y S I=\frac{Y S}{Y p}$ & Bouslama and Schapaugh (1984) \\
\hline
\end{tabular}

${ }^{1} Y_{S}$ and $Y_{P}$ are stress and optimal (potential) yield of a given genotype, respectively. $\bar{Y}_{S}$ and $\bar{Y} p$ are average yield of all genotypes under stress and optimal conditions, respectively.

\section{MATERIAL AND METHODS}

Twenty-five sorghum lines were evaluated in 2 moisture regimes. In the first, lines were well-watered throughout the growing period to allow the genotypes to affect production under non-stress conditions. In the second, lines received adequate watering from germination to the boot stage (just before flowering stage), after which no additional watering was applied. This treatment simulated post-flowering (terminal) moisture stress conditions.

Four experiments were carried in the field, 3 at Nova Porteirinha, MG (sowings on June 14, 2006; June 1, 2007; and July 2, 2008) and Teresina, PI (sowing on September 21, 2006). Both sites are located in a semi-arid region and have a very well-defined rainy season, with no rain during the trial periods (Figure 1). For sorghum drought selection, the main target is to identify stress tolerance during grain-filling period. The mean temperature and precipitation during trials at the 2 locations are shown in Figure 1.

The experimental design consisted of a randomized complete block, with treatments arranged in a factorial $25 \times 2 \times 4$ with 3 replications. Treatments were 25 lines, 2 moisture regimes, and 4 environments.

The plots consisted of 2 rows that were $5 \mathrm{~m}$ long and spaced $0.50 \mathrm{~m}$. Sowings were carried out in line with excess seeds so that after thinning, 30 days after seeding, the plot was 
left with around 200,000 plants/ha. Grain yield and indices were estimated using the equations shown in Table 1.

Analysis of variance, mean comparison, correlation between different treatments, cluster analysis of genotypes based on Euclidean distance, and biplot display were performed using the R Statistical Software.

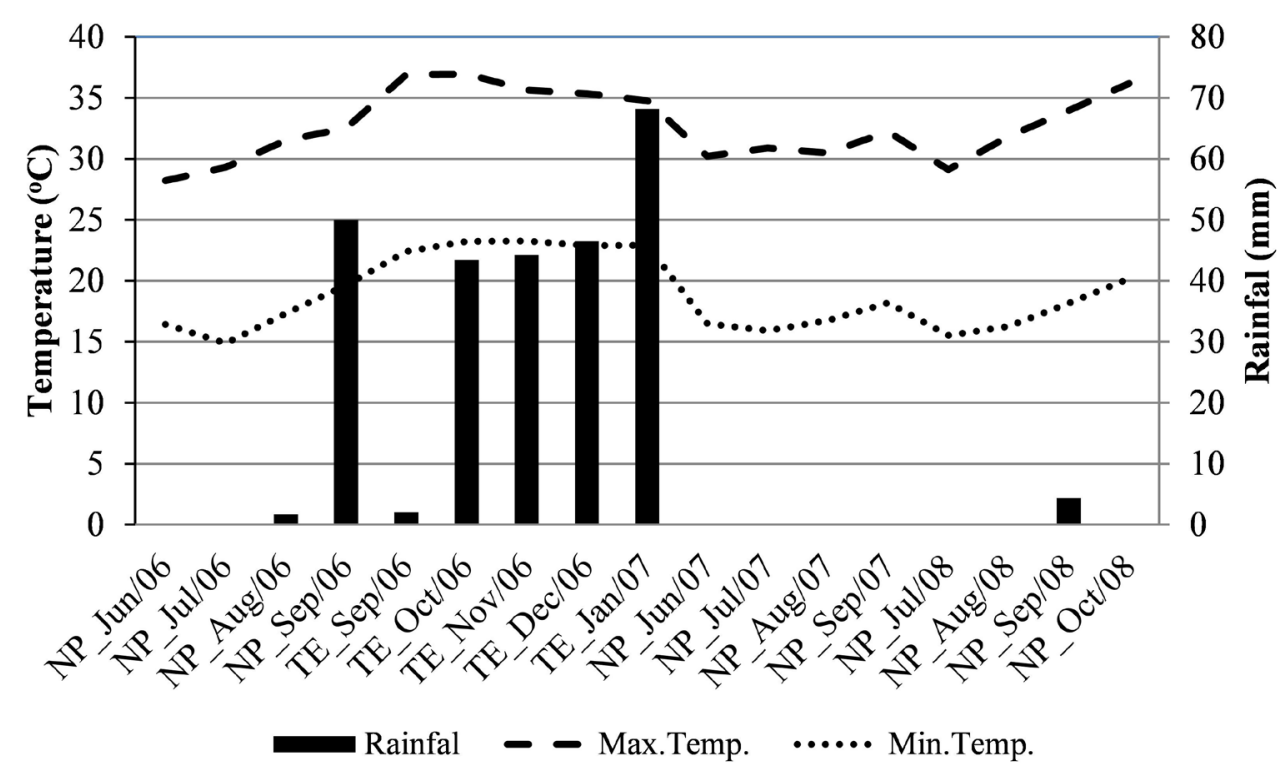

Figure 1. Mean monthly air temperature and precipitation sum during trial periods at Nova Porteirinha (NP), 2006; Teresina (TE), 2006; Nova Porteirinha, 2007, and Nova Porteirinha, 2008. Source: INMET - Instituto Nacional de Meteorologia.

\section{RESULTS AND DISCUSSION}

The effect of the experimental conditions was significant for all indices, except stress susceptibility index (SSI) and yield index (YI); this indicates that cultivar performance was very influenced by the conditions. The SSI and YI indices were not affected by the different conditions, demonstrating the stability of these indices. Therefore, these indices, if significantly correlated with yield under drought (Ys) and yield under irrigated (Yp) conditions, can be used to select for superior genotypes in one location and inferred for another (Table 2). The disadvantage of these 2 indices is that they increased the coefficient of variation, reducing the significance of the genotype effects.

The significant interaction (genotypes $\mathrm{x}$ environments) suggested that sorghum hybrids should be selected based on a combination of yield and yield stability under normal irrigation and water deficit conditions rather than on mean yield alone. However, the effect of genotype was not significant for SSI, tolerance index (TOL), and yield stability index (YSI) (Table 2). Therefore, these indices are not useful for discriminating genotypes in relation to water stress. The results suggest that there is high genetic variation among genotypes, which may be useful for selecting drought-tolerant germplasms. 


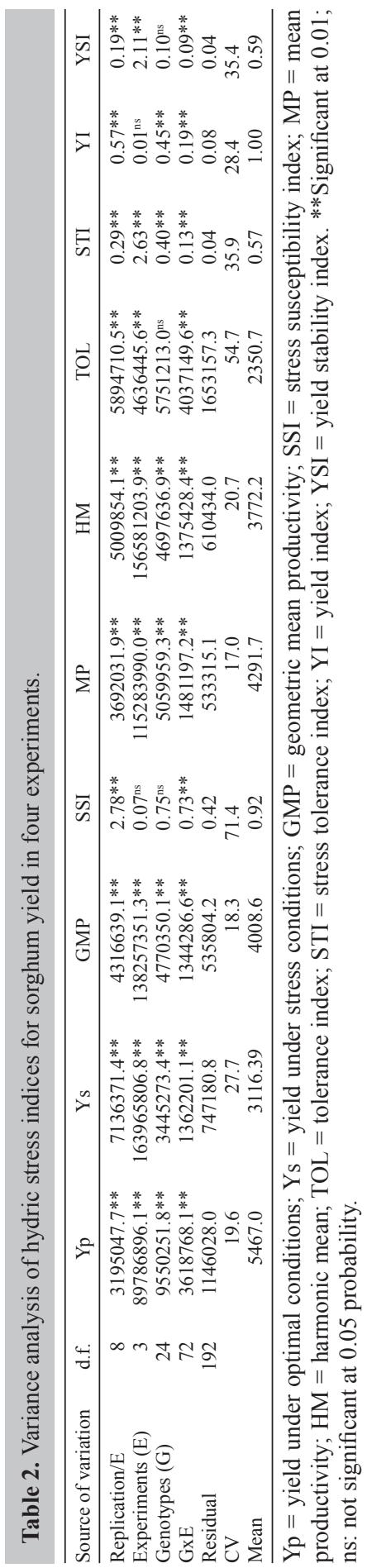


Grain yield varied from $4096 \mathrm{~kg} / \mathrm{ha}$ (line SC 283) to $7687 \mathrm{~kg} / \mathrm{ha}$ (line N 95B) under Yp and from $2341 \mathrm{~kg} / \mathrm{ha}$ (line SC 283) to $4171 \mathrm{~kg} / \mathrm{ha}$ (line 9929020) in Ys. Mean grain yield under non-stress condition was $5467 \mathrm{~kg} / \mathrm{ha}$, while under water stress condition it was $3116 \mathrm{~kg} /$ ha, indicating a reduction of $43 \%$ compared to full-irrigation conditions (Table 2). The data showed that drought stress in sorghum can significantly reduce grain yield.

The lines N 95B, BR 008B, and 9929034 showed higher grain yield under non-stress conditions, with yield averages higher than $6600 \mathrm{~kg} / \mathrm{ha}$, and the lines $9929020, \mathrm{~N} 95 \mathrm{~B}$ and 9929034 recorded higher grain yield in stress environment, with yield averages as higher as $3900 \mathrm{~kg} / \mathrm{ha}$. The genotypes N 95B and 9929034 showed good performance under both water conditions (Table 3).

\begin{tabular}{|c|c|c|c|c|c|c|c|c|c|c|c|}
\hline Code & Genotype & Yp (kg/ha) & Ys (kg/ha) & GMP & SSI & MP & HM & TOL & STI & YI & YSI \\
\hline 1 & 9409132 & 4467 & 2714 & 3392 & 0.75 & 3591 & 3222 & 1753 & 0.38 & 0.92 & 0.73 \\
\hline 2 & 9503086 & 5606 & 3165 & 4113 & 0.94 & 4385 & 3882 & 2441 & 0.57 & 1.03 & 0.58 \\
\hline 3 & 9929020 & 6275 & 4171 & 5058 & 0.73 & 5223 & 4904 & 2105 & 0.92 & 1.47 & 0.67 \\
\hline 4 & 9929034 & 6620 & 3954 & 4993 & 0.81 & 5287 & 4735 & 2665 & 0.83 & 1.26 & 0.67 \\
\hline 5 & ATF 14B & 5643 & 2433 & 3595 & 1.39 & 4038 & 3238 & 3210 & 0.43 & 0.74 & 0.43 \\
\hline 6 & ATF 46B & 4450 & 2512 & 3310 & 1.11 & 3481 & 3152 & 1939 & 0.39 & 0.84 & 0.57 \\
\hline 7 & ATF 54B & 5214 & 2392 & 3304 & 0.95 & 3803 & 2919 & 2822 & 0.38 & 0.71 & 0.49 \\
\hline 8 & ATF $8 B$ & 5247 & 3045 & 3914 & 0.90 & 4146 & 3711 & 2202 & 0.51 & 0.99 & 0.59 \\
\hline 9 & В 803 & 5100 & 3021 & 3855 & 0.97 & 4060 & 3672 & 2079 & 0.50 & 1.00 & 0.60 \\
\hline 10 & В 8911 & 4715 & 2983 & 3707 & 0.81 & 3849 & 3575 & 1732 & 0.47 & 0.98 & 0.62 \\
\hline 11 & BR 008B & 7077 & 3338 & 4661 & 1.15 & 5208 & 4237 & 3739 & 0.74 & 1.04 & 0.48 \\
\hline 12 & CMSXS230B & 5293 & 3598 & 4282 & 0.67 & 4445 & 4136 & 1695 & 0.63 & 1.12 & 0.68 \\
\hline 13 & N 95B & 7687 & 4157 & 5545 & 1.04 & 5922 & 5218 & 3531 & 1.04 & 1.32 & 0.53 \\
\hline 14 & P 89003 & 5814 & 3431 & 4432 & 1.05 & 4623 & 4256 & 2383 & 0.68 & 1.17 & 0.60 \\
\hline 15 & SC 283 & 4096 & 2341 & 3001 & 0.73 & 3219 & 2812 & 1755 & 0.31 & 0.76 & 0.60 \\
\hline 16 & SC 414-12-E & 5904 & 3521 & 4505 & 0.99 & 4712 & 4316 & 2384 & 0.71 & 1.09 & 0.58 \\
\hline 17 & SC 566-14 & 5799 & 2904 & 4007 & 1.09 & 4351 & 3715 & 2895 & 0.55 & 1.01 & 0.53 \\
\hline 18 & Tx 2737 & 5369 & 3802 & 4405 & 0.42 & 4585 & 4246 & 1567 & 0.65 & 1.20 & 0.71 \\
\hline 19 & Tx 2862 & 5731 & 2745 & 3868 & 1.27 & 4238 & 3559 & 2986 & 0.58 & 0.92 & 0.49 \\
\hline 20 & Tx 2895 & 5591 & 2602 & 3631 & 1.16 & 4097 & 3292 & 2989 & 0.45 & 0.75 & 0.45 \\
\hline 21 & Tx 2904 & 5078 & 2744 & 3587 & 1.04 & 3911 & 3336 & 2334 & 0.46 & 0.84 & 0.53 \\
\hline 22 & Tx 2907 & 4377 & 2678 & 3265 & 0.63 & 3528 & 3052 & 1699 & 0.37 & 0.81 & 0.61 \\
\hline 23 & Tx 2908 & 6486 & 3212 & 4403 & 1.20 & 4849 & 4048 & 3274 & 0.68 & 1.00 & 0.47 \\
\hline 24 & Tx 430 & 4292 & 3134 & 3475 & 0.39 & 3713 & 3281 & 1158 & 0.42 & 0.89 & 0.74 \\
\hline 25 & Tx 436 & 4749 & 3316 & 3908 & 0.72 & 4032 & 3792 & 1433 & 0.54 & 1.13 & 0.70 \\
\hline
\end{tabular}

For abbreviations, see Table 2.

The values of geometric mean productivity (GMP) ranged from $3001-5545 \mathrm{~kg} / \mathrm{ha}$ and the genotypes N 95B, 9929020, and 9929034 were the most productive $(>4993 \mathrm{~kg} / \mathrm{ha})$. Based on mean productivity (MP), yield was $3219-5922 \mathrm{~kg} / \mathrm{ha}$, indicating that these genotypes were the most productive ( $>5027 \mathrm{~kg} / \mathrm{ha}$ ). Harmonic mean $(\mathrm{HM})$ ranged from $2812-5218 \mathrm{~kg} / \mathrm{ha}$, suggesting that the genotypes N 95B, 9929020, and 9929034 are the most promising of all studied genotypes $(>4735 \mathrm{~kg} / \mathrm{ha})$. Stability tolerance index (STI) ranged from 0.3-1.0; values close to 1 indicate high stress tolerance. Genotypes 13, 3, 4, and 11 had higher values of up to 0.7 , suggesting that these genotypes were the most tolerant. YI ranged from 0.7-1.5, with genotypes 9929020, N 95B and 9929034 with the higher index $(>1.2)$. The YI selected the same genotypes of $Y s(r=0.96)$ and showed a moderate correlation with $Y p(r=0.58)$.

To determine the most desirable drought tolerance measures, the correlation coefficient between Yp, Ys, and other quantitative indices of drought tolerance were estimated (Table 4). 
Table 4. Correlation coefficients between of drought stress index, and yield under optimal and stress conditions.

\begin{tabular}{|c|c|c|c|c|c|c|c|c|c|}
\hline & Yp & Ys & GMP & SSI & MP & HM & TOL & STI & YI \\
\hline Ys & $0.63 * *$ & & & & & & & & \\
\hline GMP & $0.88 * *$ & $0.92 * *$ & & & & & & & \\
\hline SSI & $0.45^{*}$ & $-0.30^{\text {ns }}$ & $0.07^{\mathrm{ns}}$ & & & & & & \\
\hline MP & $0.95 * *$ & $0.85^{* *}$ & $0.98 * *$ & $0.19^{\text {ns }}$ & & & & & \\
\hline HM & $0.80^{* *}$ & $0.96^{* *}$ & $0.99 * *$ & $-0.02 * *$ & $0.95^{* *}$ & & & & \\
\hline TOL & $0.80^{* *}$ & $0.04^{\text {ns }}$ & $0.42 *$ & $0.82 * *$ & $0.57^{* *}$ & $0.30^{\mathrm{ns}}$ & & & \\
\hline STI & $0.87^{* *}$ & $0.91 * *$ & $0.99 * *$ & $0.08^{\text {ns }}$ & $0.97^{* *}$ & $0.98^{* *}$ & $0.42^{*}$ & & \\
\hline YI & $0.58 * *$ & $0.96^{* *}$ & $0.88 * *$ & $-0.24^{\mathrm{ns}}$ & $0.80 * *$ & $0.94 * *$ & $0.01^{\mathrm{ns}}$ & $0.88 * *$ & \\
\hline YSI & $-0.41^{*}$ & $0.40^{*}$ & $0.04^{\mathrm{ns}}$ & $-0.88^{* *}$ & $-0.12^{\mathrm{ns}}$ & $0.15^{\text {ns }}$ & $-0.83^{* *}$ & $0.02^{\mathrm{ns}}$ & $0.42^{*}$ \\
\hline
\end{tabular}

For abbreviations, see Table $2 .{ }^{*}, * *$ Significant at 0.05 and 0.01 ; ns: not significant at 0.05 probability.

The indices GMP, MP, HM, and STI were very similar to the selection based on Yp and Ys. This was confirmed by the high correlations between Yp and GMP $(r=0.88)$, MP $(r=$ $0.95)$, HM $(r=0.80)$, and STI $(r=0.87)$ and the correlation between Ys and GMP $(r=0.92)$, MP $(r=0.85)$, HM $(r=0.96)$, and STI $(r=0.91)($ Table 4).

MP is the mean production under both stress and non-stress conditions, and was highly correlated with yield under both conditions. Thus, MP can be used to identify cultivars in the tolerant group. A limitation of using MP is that it is very influenced by extreme values, i.e., yields very low or very high, which was not observed in this study.

SSI values varied from $0.39-1.39$, which were significantly and negatively correlated with yield under stress and positively correlated with the TOL index. A low SSI value is preferred, and the genotypes Tx 2907, Tx 2737, and Tx 430 showed the lowest indices. These genotypes were not selected based on the other indices.

TOL ranged from $1158-3739 \mathrm{~kg} / \mathrm{ha}$. Lower or negative TOL indices indicate tolerance to water stress. Therefore, the genotypes Tx 430, Tx 436, and Tx 2737 were more tolerant $(<1567 \mathrm{~kg} / \mathrm{ha})$. Notably, the less tolerant genotypes were BR 008B and N 95B ( $>3530 \mathrm{~kg} / \mathrm{ha})$, in contrast to the indices GMP, STI, MP, and HM. This was verified by the moderate correlation observed for TOL with GMP $(r=0.42)$, MP $(r=0.57)$ and was not significant with HM $(\mathrm{r}=0.30)$. A positive correlation between TOL and yield under normal conditions (Yp) and a negative correlation between TOL and yield under stress (Ys) suggested that selection based on TOL resulted in reduced yield under well-watered conditions. TOL appears to be useful for selecting genotypes with high yield under stress, but failed to select genotypes with good yield in both environments. Similar results have been reported in several crops such as barley (Rizza et al., 2004), wheat (Sio-Se Marde et al., 2006), durum wheat (Talebi et al., 2009; Shiri et al., 2010), and chickpea (Talebi et al., 2011).

YSI ranged from 0.43-0.74; a higher rate indicates greater stability. Genotypes that showed higher indices include Tx 430, 9409132, Tx 2737, and Tx 436 whose values were greater than 0.70 (Table 3). Similarly to the SSI and TOL, correlations between YSI and GMP, STI, MP, and HM were low $(r=0.04, r=0.02, r=-0.12$, and $r=0.15$, respectively), indicating that similar genotypes were not selected (Table 4).

A suitable index must be significantly correlated with yield in any of the 2 environments and a lower coefficient of variation. The indices SSI, TOL, and YSI showed the lowest correlation with Ys (Table 4), and the highest coefficient of variation (Table 2). YI was significantly correlated with Ys and Yp, but showed a higher coefficient of variation than the GMP, MP, and HM indices. 
The results indicated that there were positive and significant correlations among Yp and Ys with GMP, MP, HM, and STI; thus, these parameters may be better predictors of Yp and Ys than TOL, SSI, YSI, and YI. The observed results are consistent with those of Fernández (1992) in mungbean, Farshadfar and Sutka (2002a,b) in wheat and maize and Golabadi et al. (2006) in durum wheat.

STI was significantly correlated with Yp and Ys, but had a higher coefficient of variation than GMP. STI was calculated based on the GMP index and therefore a high positive correlation was observed between these indices (0.963), which is in agreement with Fernández (1992) and Mozaffari et al. (1996). Therefore, GMP is a better selection factor than STI.

Selection based on a combination of indices may be more useful for improving drought resistance of sorghum, but the correlation coefficient is useful for determining the degree of overall linear association between any 2 attributes. Thus, a better approach than a correlation analysis such as biplot analysis is required to identify superior genotypes for both stress and non-stress environments. Principal component analysis (PCA) revealed that the first PCA explained $65 \%$ of the total variation and was highly and positively correlated with Yp, Ys, GMP, MP, HM, and STI (Figure 1). Thus, the first dimension can be considered the yield potential and drought tolerance. Considering the high and positive values determined through biplot analysis, genotypes with high values for this index will be high-yielding under stress and non-stress environments. Therefore, genotypes belonging to numbers 13, 3, and 4 were superior genotypes under both conditions in all locations. The second PCA explained 32\% of the total variability. Genotypes belonging to numbers 15, 22, and 6 showed the worst MP, GMP, and STI values. Genotypes with higher PCA are more suitable for non-stressed than stressed environments.

The biplot shows that the best index for evaluating genotypes under stress condition (Ys) is YI, and genotype 3 (9929020) was found to be best suited to water stress. A similar result was found by Yarnia et al. (2011) and Darvishzadeh et al. (2010). In contrast, vectors for the indices MP, STI, GMP, and HM remained between the Yp and Ys vectors, indicating that these indices are very similar for drought selection. GMP and STI appeared to be the best indices for dividing the angle symmetrically between Yp and Ys. Therefore, these factors can be used to select for genotypes that are better adapted to both conditions. A similar conclusion was reached by Yarnia et al. (2011) in studying rape. Darvishzadeh et al. (2010) examined sunflower in one location, and found that tolerant indices including MP, GMP, and HM were suitable for drought-tolerant genotype selection. However, based on the biplot presented by these authors, GMP is the most appropriate index for selection under stressed and non-stressed conditions. Kharrazi and Rad (2011) suggested that MP and STI are useful indicators for selecting tolerant genotypes.

The correlation coefficient between any 2 indices was nearly the cosine of the angle between their vectors. Thus, $r=\cos 180^{\circ}=-1, \cos 0^{\circ}=1$, and $\cos 90^{\circ}=0$ (Yan and Rajcan, 2002). The most prominent relationships revealed by these biplots were: i) a strong negative association between SSI and TOL with YSI, as indicated by the large obtuse angles between their vectors, ii) a nearly zero correlation between SSI with GPM, MP, HM, and STI, as well as SSI and TOL with Ys and YI, as indicated by the nearly perpendicular vectors, and iii) a positive association between Yp and Ys with MP, GMP, HM, and STI, as indicated by the acute angles (Figure 2). The results obtained from the biplot graph confirmed the correlation analysis results (Table 4). 


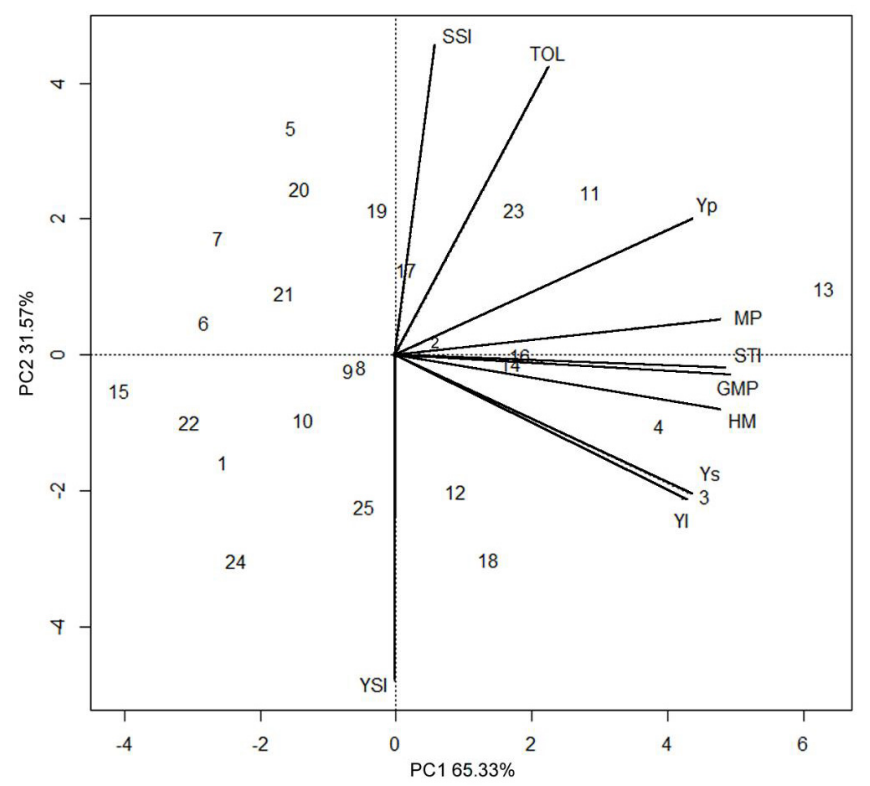

Figure 2. Biplot diagram of 25 sorghum genotypes and 8 drought indices. The indices are indicated using uppercase letters (see Table 2, for abbreviations), and each genotype is represented with numbers. Genotype codes: see Table 3.

Using indices with the highest correlation with Yp and Ys (GMP, MP, HM, YI, and STI), unweighted pair group with arithmetic mean cluster analyses were conducted to group the genotypes (Figure 3). The results were consistent with those of biplot analysis (Figure 2). The advantage of this approach is that it can be used to calculate distances between genotypes. The distance between the 2 greater clusters was 1300 units. The top cluster grouped genotypes with low yield, while the lower cluster contained genotypes with higher yield. Within the cluster of superior genotypes, 3,4 , and 13 were 1000 units away from other members of the sub-cluster. This result indicates the superiority of these genotypes, and efficiency of these 5 indices for classifying genotypes under both stress and non-stress conditions.

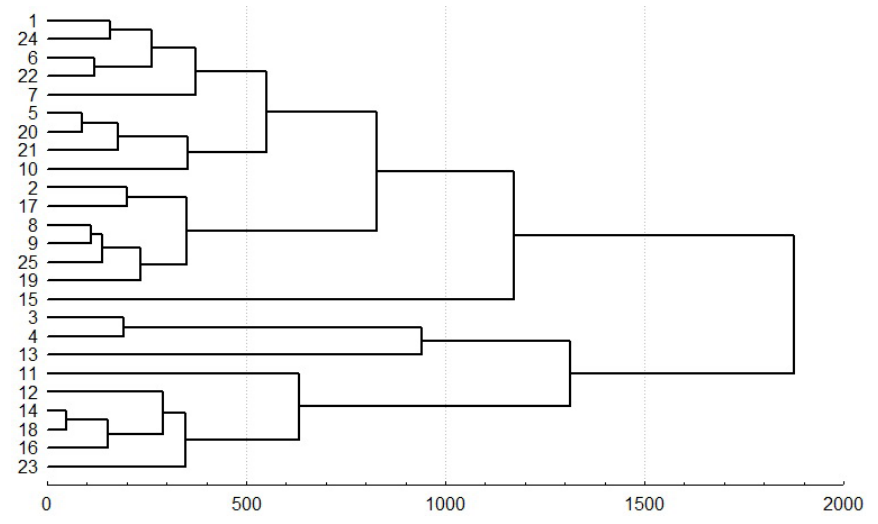

Figure 3. Dendrogram from UPGMA cluster analysis of genotypes based on drought tolerance indices (GMP, MP, HM, STI, and YI) and grain yield of grain sorghum lines, in both normal and stress environments. Genotype codes: see Table 3. 


\section{CONCLUSIONS}

Drought stress significantly affected the yield of sorghum lines, causing a reduction of $43 \%$ compared to the full-irrigation condition. GMP, MP, HM, and STI were more suitable indices for selecting sorghum lines tolerant to drought.

Selection using these indices can be useful for identifying a cultivar with desirable yield under both stress and non-stress conditions (group A), although the selection was conducted based on PCA results (by using several indices rather than only one index).

Based on yield under non-stressed and stressed conditions, the lines 9929020, 9929034, and N 95B were the best performing genotypes. The indices SSI, TOL, and YSI were not correlated with either Yp or Ys. YI may also be useful when the selection program goal is to identify lines in a water stress environment.

\section{ACKNOWLEDGMENTS}

The authors thank the institutions Embrapa Maize and Sorghum, Research Foundation of the State of Minas Gerais (FAPEMIG), and the National Council of Scientific and Technological Development (CNPq) for the financial support.

\section{REFERENCES}

Betrán FJ, Beck D, Banziger M and Edmeades GO (2003). Genetic analysis of inbred and hybrid grain yield under stress and nonstress environments in tropical maize. Crop Sci. 43: 807-817.

Blum A (1988). Plant Breeding for Stress Environments. CRC Press, Inc., Boca Raton.

Bouslama M and Schapaugh WT (1984). Stress tolerance in soybean. Part 1: Evaluation of three screening techniques for heat and drought tolerance. Crop Sci. 24: 933-937.

CONAB (Companhia Nacional de Abastecimento) (2013). Acompanhamento de Safra Brasileira: Grãos, Décimo Segundo Levantamento, Setembro 2013. CONAB, Brasília.

Darvishzadeh R, Pirzad A, Hatami-Maleki H, Kiani SP, et al. (2010). Evaluation of the reaction of sunflower inbred lines and their F-1 hybrids to drought conditions using various stress tolerance indices. Span. J. Agric. Res. 8: 1037-1046.

Farshadfar E and Sutka J (2002a). Multivariate analysis of drought tolerance in wheat substitution lines. Cereal Res. Comm. 31: 33-39.

Farshadfar E and Sutka J (2002b). Screening drought tolerance criteria in maize. Acta Agron. Hung. 50: 411-416.

Fernández GCJ (1992). Effective Selection Criteria for Assessing Plant Stress Tolerance. In: Proceedings of the International Symposium on Adaptation of Vegetables and Other Food Crops in Temperature and Water Stress (Kuo CG, ed.). Publication, Tainan, Taiwan.

Fischer RA and Maurer R (1978). Drought resistance in spring wheat cultivars. I. Grain yield responses. Aust. J. Agric. Res. 29: 897-912.

Gavuzzi P, Rizza F, Palumbo M, Campaline RG, et al. (1997). Evaluation of field and laboratory predictors of drought and heat tolerance in winter cereals. Can. J. Plant Sci. 77: 523-531.

Golabadi M, Arzani A and Maibody SAM (2006). Assessment of drought tolerance in segregating populations in durum wheat. Afr. J. Agric. Res. 5: 162-171.

Hall AE (1993). Is Dehydration Tolerance Relevant to Genotypic Differences in Leaf Senescence and Crop Adaptation to Dry Environments? In: Plant Responses to cellular Dehydration During Environmental Stress (Close TJ and Bray EA, eds.). American Society of Plant Physiologists, Rockville, 1-10.

Jafari A, Paknejad F, Jami M and Ahmadi AL (2009). Evaluation of selection indices for drought tolerance of corn (Zea mays L.) hybrids. Int. J. Plant Prod. 3: 33-38.

Kharrazi MAS and Rad MRN (2011). Evaluation of sorghum genotypes under drought stress conditions using some stress tolerance indices. Afr. J. Biotechnol. 10: 13086-13089.

Mohammadi R, Armion M, Kahrizi D and Amri A (2010). Efficiency of screening techniques for evaluating durum wheat genotypes under mild drought conditions. Int. J. Plant Prod. 4: 11-24. 
Mozaffari K, Arshi Y and Zeinali H (1996). Response on the effects of water stress on some morpho physiological traits and yield components of sunflower seed and plant. J. Plant Nutr. 12: 24-33.

Mutava RN, Prasad PVV, Tuinstra MR, Kofoid KD, et al. (2011). Characterization of sorghum genotypes for traits related to drought tolerance. Field Crops Res. 123: 10-18.

Ramirez P and Kelly JD (1998). Traits related to drought resistance in common bean. Euphytica 99: 127-136.

Rizza F, Badeckb FW, Cattivellia L, Lidestric O, et al. (2004). Use of a water stress index to identify barley genotypes adapted to rainfed and irrigated conditions. Crop Sci. 44: 2127-2137.

Rosielle AA and Hambling J (1981). Theoretical aspects of selection for yield in stress and non stress environments. Crop Sci. 21: 943-946.

Shiri M, Choukan R and Aliyev RT (2010). Drought tolerance evaluation of maize hybrids using biplot method. Trends Appl. Sci. Res. 5: 129-137.

Sio-Se Marde A, Ahmadi A, Poustini K and Mohammadi V (2006). Evaluation of drought resistance indices under various environmental conditions. Field Crops Res. 98: 222-229.

Talebi R, Fayaz F and Naji AM (2009). Effective selection criteria for assessing drought stress tolerance in durum wheat (Triticum durum Desf). Gen. Appl. Plant Physiol. 35: 64-74.

Talebi R, Baghebani N, Karami E and Ensafi MH (2011). Defining selection indices for drought tolerance in chickpea under terminal drought stresses. J. Appl. Biol. Sci. 5: 38.

Yan W and Rajcan I (2002). Biplot Analysis of Test Sites and Trait Relations of Soybean in Ontario. Crop Sci. 42: 11-20.

Yarnia M, Arabifard N, Khoei FR and Zandi P (2011). Evaluation of drought tolerance indices among some winter rapeseed cultivars. Afr. J. Biotechnol. 10: 10914-10922. 